Lepr Rev (1996) 67, 280-286

\title{
Primary resistance to single and multiple drugs in leprosy-a mouse footpad study
}

\author{
V. P. SHETTY, M. W. UPLEKAR \& N. H. ANTIA \\ The Foundation for Medical Research, 84-A, R. G. Thadani Marg, \\ Worli, Bombay 400 018, India
}

Accepted for publication 1 July 1996

\begin{abstract}
Summary Skin biopsy homogenates obtained from three cases of lepromatous leprosy with no prior history of antileprosy treatment were tested in the mouse footpad for the sensitivity of Mycobacterium leprae to multiple drugs.

One of the inocula was sensitive to all the three drugs tested using the highest concentration each of DDS $0.01 \mathrm{~g} \%$, RFP $0.03 \mathrm{~g} \%$ and CLF $0.01 \mathrm{~g} \%$. The 2nd inocula showed growth in the presence of $0.01 \mathrm{~g} \%$ DDS only. While the 3rd inocula (Pt. KU) tested resistant to all the three drugs in the first, i.e. man to mouse, as well as in the second passage, i.e. mouse to mouse.
\end{abstract}

\section{Introduction}

Since its introduction in $1982,{ }^{1}$ multidrug therapy (MDT) is heralded as one of the most important and stimulating contributions to leprosy control. ${ }^{2}$ Data from field programmes also indicate a high degree of efficiency of WHO/MDT after about 10 years of follow up. ${ }^{3}$ While it took over a decade to first suspect dapsone resistance, its prevalence has since increased at an alarmingly high rate. ${ }^{4,5}$ In a much shorter period thereafter, secondary resistance has been reported with rifampicin, clofazimine, ethionamide and prothionamide ${ }^{6-10}$ To date, however, primary resistance to multiple drugs in leprosy has not been documented.

We report here a study on 3 cases of previously untreated lepromatous leprosy of which two exhibited primary resistance to single and multiple drugs of MDT respectively using the well established mouse footpad technique. Their significance is discussed.

\section{Materials and methods}

Skin biopsy homogenates obtained from three cases of lepromatous leprosy with no prior history of antileprosy treatment, were tested individually using mouse footpad for the growth of $M$. leprae and their sensitivity to multiple drugs. The patients in question, two males aged 40 and 29 years and a female aged 19 years were part of an ofloxacin trial 
Table 1. Inocula 1 - Patient KS. Bacterial count per footpad in normal and drug-treated mice at the 12 th month (counts $\times 104)$.

\begin{tabular}{lccccc}
\hline No. & No Rx & $\begin{array}{c}\text { DDS (1) } \\
0.01 \mathrm{~g} \%\end{array}$ & $\begin{array}{c}\text { RFP (2) } \\
0.03 \mathrm{~g} \%\end{array}$ & $\begin{array}{c}\text { CLF (3) } \\
0.01 \mathrm{~g} \%\end{array}$ & $\begin{array}{c}\text { Mixture } \\
(1+2+3)\end{array}$ \\
\hline M1 & $80 \cdot 25$ & $1 \cdot 5$ & 0 & 0 & 0 \\
M2 & $81 \cdot 75$ & $5 \cdot 25 \dagger$ & 0 & $0 \cdot 75$ & 0 \\
M3 & $48 \cdot 00$ & $15 \cdot 06^{*}$ & 0 & 0 & 0 \\
M4 & 186.00 & $48 \cdot 00^{*}$ & 0 & 0 & 0 \\
M5 & - & $4 \cdot 5 \dagger$ & 0 & $2 / 5$ & 0 \\
\hline Take & $4 / 4$ & $5 / 5$ & $0 / 5$ & $(40)$ & $0 / 5$ \\
$(\%)$ & $(100)$ & $(100)$ & $(0)$ & & $(0)$ \\
\hline
\end{tabular}

$* \geq$ ten-fold growth.

$\dagger \geq$ five-fold growth.

0 No AFB seen in more than 200 fields.

Table 2. Inocula 2 - Patient SB. Bacterial count per footpad in normal and drug-treated mice at the 12 th month $\left(\right.$ counts $\left.\times 10^{4}\right)$.

\begin{tabular}{|c|c|c|c|c|c|}
\hline No. & No RX & $\begin{array}{l}\text { DDS (1) } \\
0 \cdot 01 \mathrm{~g} \%\end{array}$ & $\begin{array}{l}\text { RFP (2) } \\
0.03 \mathrm{~g} \%\end{array}$ & $\begin{array}{l}\text { CLF (3) } \\
0.01 \mathrm{~g} \%\end{array}$ & $\begin{array}{c}\text { Mixture } \\
(1+2+3)\end{array}$ \\
\hline M1 & $51 \cdot 75$ & 0.75 & 0 & 0 & 0 \\
\hline M2 & 33.75 & 0 & 0 & 0 & 0 \\
\hline M3 & 30.03 & 0 & 0 & 0 & 0 \\
\hline M4 & $31 \cdot 5$ & 0 & 0 & 0 & 0 \\
\hline M5 & - & 0.75 & 0 & 0 & 0 \\
\hline M6 & - & 0.75 & 0 & 0 & 0 \\
\hline $\begin{array}{l}\text { Take } \\
(\%)\end{array}$ & $\begin{array}{c}4 / 4 \\
(100)\end{array}$ & $\begin{array}{l}3 / 6 \\
(50)\end{array}$ & $\begin{array}{l}0 / 6 \\
(0)\end{array}$ & $\begin{array}{l}0 / 6 \\
(0)\end{array}$ & $\begin{array}{l}0 / 6 \\
(0)\end{array}$ \\
\hline
\end{tabular}

Table 3. Inocula 3 - Patient KU. Bacterial count per footpad in normal and drug-treated mice at the 12 th month $\left(\right.$ counts $\left.\times 10^{4}\right)$.

\begin{tabular}{|c|c|c|c|c|c|}
\hline No. & No Rx & $\begin{array}{l}\text { DDS (1) } \\
0.01 \mathrm{~g} \%\end{array}$ & $\begin{array}{l}\text { RFP (2) } \\
0.03 \mathrm{~g} \%\end{array}$ & $\begin{array}{l}\text { CLF (3) } \\
0.01 \mathrm{~g} \%\end{array}$ & $\begin{array}{c}\text { Mixture } \\
(1+2+3)\end{array}$ \\
\hline M1 & $97 \cdot 5$ & $9 \cdot 00 \dagger$ & $4.5 \dagger$ & 0 & $0 \cdot 75$ \\
\hline M2 & $60 \cdot 75$ & $1 \cdot 5$ & $3 \cdot 00$ & $1 \cdot 5$ & $0 \cdot 75$ \\
\hline M3 & $178 \cdot 00$ & 3.00 & 0 & $1 \cdot 5$ & 0.75 \\
\hline M4 & $65 \cdot 25$ & $12 \cdot 00^{*}$ & 0 & $3 \cdot 75$ & 0 \\
\hline M5 & - & $1 \cdot 50$ & $60 \cdot 00^{*}$ & $1 \cdot 5$ & 0 \\
\hline M6 & - & $7 \cdot 50 \dagger$ & 0 & $6 \cdot 00 \dagger$ & - \\
\hline $\begin{array}{l}\text { Take } \\
(\%)\end{array}$ & $\begin{array}{c}4 / 4 \\
(100)\end{array}$ & $\begin{array}{c}6 / 6 \\
(100)\end{array}$ & $\begin{array}{l}3 / 6 \\
(50)\end{array}$ & $\begin{array}{c}5 / 6 \\
(83 \cdot 3)\end{array}$ & $\begin{array}{c}3 / 5 \\
(60)\end{array}$ \\
\hline
\end{tabular}

$* \geq 10$-fold.

$\dagger \geq 5$-fold.

0 No AFB seen in more than 200 fields. 
conducted in one of the leprosy centres in Bombay. All three patients presented with diff used nodular lesions. The bacteria were harvested from the skin biopsies using the standard protocol. ${ }^{11}$ Their bacterial index (BI) were more than $5+$ their and morphological index (MI) were over $4 \%$. Ten thousand bacilli each were injected into both the hind footpads of 3-4 months-old nonimmunosuppressed Swiss white (S/W) female mice. A test for sensitivity to a single large dose each of diaminodiphenylsulphone (DDS $0.01 \mathrm{~g} \%$ ) rifampicin (RFP $0.03 \mathrm{~g} \%$ ) clofazimine (CLF $0.01 \mathrm{~g} \%$ ) and to a mixture of all three drugs in the same concentration were set, along with an untreated control group of mice. All the drugs were given to the test mice through the feed from day zero (continuous method). ${ }^{12}$ Drugs were incorporated into the commercially available powdered mash feed, through wet mixing and blending.

The harvesting of footpads and recordings of $M$. leprae growth in the footpads of the control group of mice were carried out at monthly intervals beginning from the 6th month, while drug treated mice were harvested only at the 12th month following infection. A minimum of 5 to 6 counts each (left and right pooled harvest) were obtained at the 12 th month.

Suspensions of $M$. leprae derived from two sources, i.e. one from the untreated lepromatous leprosy patient (KU) and the other from an armadillo biopsy (obtained from Ellenor Storrs) were heat killed and injected into the footpads of the normal mice with an inocula containing 10,000 bacilli in $0.03 \mathrm{ml}$. Harvestings were done at monthly intervals beginning from the 1 st month and were followed up to the 12 th month.

\section{CONFIRMATION OF DRUG RESISTANCE IN SECOND PASSAGE}

Only the drug-resistant organisms derived from mice treated with DDS ( $0 \cdot 1 \mathrm{~g} \%)$, RFP $(0.3 \mathrm{~g} \%), \mathrm{CLF}(0.01 \mathrm{~g} \%)$ and the mixture, in the primary passage for inocula No. 3 (Pt $\mathrm{KU})$ were repassaged into groups of 10 mice each and were maintained in the absence and presence of respective drugs for which they were resistant. Footpad harvests were carried out at the 12 th month.

\section{Results}

Normal growth curves were obtained in the footpads of control (untreated) S/W mice with all the three inocula. Results obtained in the drug-treated mice using these inocula were as follows:

Primary drug-screening test in normal Swiss white mice:

Inocula 1. (patient KS, aged 40, male) Harvests done at the 12 th month showed no detectable count in the footpads of mice treated with $0.03 \mathrm{~g} \%$ RFP and with the mixture of all three drugs. Two out of 5 CLF treated mice showed a very small count $\left(0.75 \times 10^{4}\right.$ not significant), while in DDS-treated mice there were counts in all the 5 mice (left and right pooled harvest). Two of the counts were more than 10 -fold while in others it was less than 10-fold, nevertheless suggesting, primary resistance to $0.01 \mathrm{mg} / \%$ DDS which is equivalent to $100 \mathrm{mg}$ human dose ( See Table 1).

Inocula 2. (patient SB, aged 19, female) At the 12th month there were no detectable counts in any of the mice treated with RFP, CLF and the mixture. The DDS-treated group of mice showed a marginal count (less than 10-fold) in 3 out of 6 mice suggesting 
that this inocula was fully sensitive to RFP and CLF and probably a low-grade resistance to DDS (See Table 2).

Inocula 3. (patient KU, aged 29, male) There was a good take in the footpads of mice treated using DDS, RFP and CLF tested individually, while mice treated with the combination of drugs showed a small count (not significant) in 3 out of 5 mice (see Table 3). The percentage of footpads showing counts as well as the per footpad counts were highest in the DDS treated mice followed by RFP, CLF and the mixture suggesting the presence of a subpopulation each of $M$. leprae that were resistant to all the three drugs tested individually.

\section{CONFIRMATION OF DRUG RESISTANCE IN THE SECOND PASSAGE}

As mentioned earlier only the drug-resistant strains of $M$. leprae obtained in the primary screening of inocula number 3 (patient $\mathrm{KU}$ ) were reinoculated into the footpads of normal Swiss white mice (inocula size were approximately $1 \times 10^{3}$ ) and were further maintained both in the absence $(5$ mice) and presence $(5$ mice $)$ of respective drugs for which they were resistant.

In the second passage, the respective drug-resistant strains again showed a good-fold increase and very good morphological index, i.e. $15-20 \%$, in the footpads of both drugtreated and untreated mice at the 12th month, thus confirming their continued resistance to these drugs (Table 4). However, it was noted that the percentage take in the second passage ranged between 20 and $80 \%$. Moreover inocula derived from DDS-treated mice (DDS resistant) showed a better take $(60 \%)$ in the presence of $0.01 \mathrm{~g} \%$ DDS than the control group of mice (take $=25 \%)$.

Two experiments using heat-killed $M$. leprae derived from two different sources, i.e. inocula 3 patient KU and armadillo-derived $M$. leprae (see Table 5) showed presence of acid-fast bacilli in the footpads of normal Swiss white mice till the end of the 6th month. There was a steady decline in the percentage take with time. Moreover the average per footpad count in these experiments 1 and 2 (namely, $0 \cdot 3 \pm 0.21$ and $0.4 \pm 0 \cdot 25$ respectively) were less than the original inocula at any point in time.

Table 4. Drug-resistant bacteria derived from inocula 3 (Pt-KU) in second passage (mouse to mouse). M. leprae count/footpad $\times 10^{5}$ at 12 th month in the absence $(\mathrm{C})$ and presence of respective drugs.

\begin{tabular}{|c|c|c|c|c|c|c|c|c|}
\hline & \multicolumn{2}{|c|}{$1^{\circ} \mathrm{DDS}$ Res } & \multicolumn{2}{|c|}{$1^{\circ}$ RFP Res } & \multicolumn{2}{|c|}{$1^{\circ} \mathrm{CLF}$ Res } & \multicolumn{2}{|c|}{$1^{\circ} \mathrm{Mix}$ Res } \\
\hline & $\mathrm{C}^{*}$ & $\begin{array}{c}\text { DDS } \dagger \\
0.019 \%\end{array}$ & $\mathrm{C}^{*}$ & $\begin{array}{c}\text { RFP } \dagger \\
0.039 \%\end{array}$ & $\mathrm{C}^{*}$ & $\begin{array}{c}\text { CLF } \dagger \\
0.019 \%\end{array}$ & $\mathrm{C}^{*}$ & Mix ${ }^{\dagger}$ \\
\hline M1 & $20 \cdot 3$ & $20 \cdot 3$ & $6 \cdot 8$ & $6 \cdot 8$ & $3 \cdot 4$ & $3 \cdot 4$ & 0 & ND \\
\hline M2 & 0 & $13 \cdot 6$ & $6 \cdot 8$ & 0 & $8 \cdot 5$ & 0 & $6 \cdot 8$ & ND \\
\hline M3 & 0 & 0 & $1 \cdot 4$ & 0 & 0 & $5 \cdot 1$ & 0 & ND \\
\hline M4 & 0 & $6 \cdot 8$ & 0 & 0 & $6 \cdot 8$ & $1 \cdot 7$ & 0 & ND \\
\hline M5 & - & 0 & - & - & $1 \cdot 7$ & - & 0 & ND \\
\hline Take & $1 / 4$ & $3 / 5$ & $3 / 4$ & $1 / 4$ & $4 / 5$ & $3 / 4$ & $1 / 5$ & \\
\hline$\%$ & $(25)$ & (60) & $(75)$ & (25) & (85) & (75) & (20) & \\
\hline
\end{tabular}

$\mathrm{C}^{*}$, mice on normal diet.

$\dagger$, not defined.

ND, not done.

0 , no bacilli seen in $>100$ fields. 
Table 5. Profile of bacterial clearance. Heat killed M. leprae in the footpads of normal S/W mice.

\begin{tabular}{lcc}
\hline & $\begin{array}{c}\text { Expt. 1 } \\
\text { armadillo } \\
\text { M. leprae }\end{array}$ & $\begin{array}{c}\text { Expt. 2 } \\
\text { human } \\
\text { M. leprae (KU) }\end{array}$ \\
\hline 1st & $3 / 4(75 \%)^{*}$ & $3 / 4$ \\
2nd & $2 / 4(50 \%)$ & - \\
3rd & $2 / 4$ & $2 / 4$ \\
4th & $1 / 4$ & - \\
5th & $3 / 4$ & - \\
6th & $1 / 4$ & 0 \\
7th & 0 & 0 \\
8th & 0 & 0 \\
9th & 0 & 0 \\
10th & 0 & 0 \\
11th & 0 & $0 / 6$ \\
12th & $0 / 10$ & \\
\hline
\end{tabular}

* Number showing M. leprae count. Number of harvests.

\section{Discussion}

Drug susceptibility testing by the mouse footpad technique is considered the most reliable. ${ }^{6}$ Primary dapsone-resistant patients verified by the mouse footpad technique were first reported in the year $1977 .{ }^{5}$ Subsequently several surveys carried out worldwide to assess the prevalence of primary and secondary resistance to DDS showed an alarming increase in the annual incidence rate and prevalence of DDS-resistant leprosy. ${ }^{1}$ In addition secondary resistance to other bactericidal drugs such as rifampicin, ethionamide and clofazimine also became apparent using the mouse footpad method. ${ }^{6}$

In the present study inocula derived from one of the untreated patients (KU) revealed subpopulations of $M$. leprae that were primarily resistant to DDS, RFP and CLF at the highest concentrations, in both primary and secondary screenings. While it was not very surprising to find primary resistance to DDS in two out of three patients considering the high incidence of DDS resistance that was prevailing since 1982, ${ }^{1}$ primary resistance to multiple drugs has not been documented to date to the best of our knowledge. However there are recent reports indicating clinical evidence of nonresponsiveness to MDT both in paucibacillary and multibacillary cases of leprosy. ${ }^{13-15}$ In one of the multibacillary cases bacteria were subsequently shown to be resistant to all the three drugs using mouse footpads. ${ }^{15}$

One of the findings that we are unable to explain is the poor percentage take that was obtained in the second passage, particularly with DDS-resistant organisms that were maintained in the absence of DDS (see Table 4). This was unlike the earlier experience where isolates of dapsone-resistant $M$. leprae have shown a better take in the subsequent passage. $^{5}$

The drugs given through feed prepared in the laboratory on a weekly basis were indeed effective was ascertained from the results obtained with three different inocula that were tested more or less simultaneously using identical protocol. In a study carried 
out at Karigiri, rifampicin mixed with feed prepared in a similar manner was systematically tested and was found to be effective in controlling the growth of $M$. leprae in the footpads of mice. ${ }^{16}$ To exclude technical error one of the controls used in the present study was to in ject an equal number of heat-killed $M$. leprae into the footpads of normal mice and record the counts at regular intervals using different inocula. It was noteworthy that the number of acid-fast organisms recovered at any point were less than the inocula, and there was a steady decline in the number of positive harvests in the footpads of normal mice. Also no acid-fast organisms were recorded (in over 200 fields) beyond 6 months in any of these mice.

Indeed one of the criteria for multiplication of $M$. leprae in the footpads is $10^{5}$ per footpad, i.e. at least a 10 -fold increase. ${ }^{17}$ Special mention must be made of the limitations of the technique as a whole and the possible underlying significance of some of the results obtained in the present study using mouse footpads. Unlike the standard protocol ${ }^{17}$ only a single concentration of each drug were tested, thus limiting the extrapolation of the results. On the other hand, in the normal Swiss white strain of mice that are routinely in use in our laboratory, the platue phase counts recorded were of ten less than 10 -fold, ${ }^{18}$ which could either be a limitation of the technic or a mice strain related variance or both. Under the circumstances we are inclined to put forward an argument that some of the 'NOT significant counts' obtained at the 12th month in the present study that are recorded in Tables 1, 2 and 3 could well be an indication of presence of a 'smaller' subpopulation of $M$. leprae that were refractory to the respective drugs and to their mixture. Admittedly the inclusion of serial dilution of drugs and harvesting at more intervals might have yielded a more clearer picture. However significance of these findings cannot be underscored and demand a more broad-based large-scale study.

\section{Acknowledgments}

Patients and the clinical details were provided by Dr Kharkar of MLSM and biopsies were done by Dr S Arolkar of FMR. We thank Dr Nerges F. Mistry in the preparation of the manuscript and Ms Mrudula Save for technical help. Ms Jayalakshmy did the typing. Financial assistance in part was from LEPRA, UK.

\section{References}

${ }^{1}$ World Health Organization, 1982. Chemotherapy of leprosy for control programmes. Report of a WHO Study Group, Geneva, (WHO Technical Report Series No. 675).

2 Noordeen SK. Elimination of leprosy as a public health problem: progress and prospects. Bull World Health Organ, 1995; 73: 1-6.

3 Noordeen SK. Leprosy control through multidrug therapy. Bull World Health Organ, 1991; 69: 263-269.

${ }^{4}$ Pettit JH, Rees RJE. Sulphone resistance in leprosy; an experimental and clinical study. Lancet, 1964; 2: 673-674.

5 Pearson JMH, Haile CTS, Rees RJW. Primary dapsone-resistant leprosy. Lepr Rev, 1977; 48: $129-132$.

6 Ji B. Drug resistance in leprosy-a review. Lep Rev. 1985; 50: 139-142.

7 Jacobson RR, Hastings RC. Rifampicin resistant leprosy. Lancet, 1976; 2: 1304-1305.

8 Grosset JH, Guelpa-Lauras CC, Bobin P et al. Study of 39 documented relapses of multibacillary leprosy after treatment with rifampicin. Int J Le pr, 1989; 57: 607-612.

9 Pattyn SR, Colston MI. Cross-resistance amongst thiambutosine, thiacetazone, ethionamide and prothianamide with Mycobacterium leprae. Le pr Rev., 1978; 49: 324-326. 
${ }^{10}$ Warndorff-van Dipen T. Clofazimine-resistant leprosy-a case report. Int J Lepr, 1982; 50: $139-142$.

11 Shepard CC. The experimental disease that follows the injection of human leprosy bacilli into foot pads of mice. J Exp Med, 1960; 112: 445-454.

12 Shepard CC, Chang YT. The effect of several antileprosy drugs on multiplication of human leprosy bacilli in footpads of mice. Proc Soc exp Biol Medi, 1963; 109: 636-638.

13 Brakel W Van, Kist P, Nobles S, Tooleb LO. Relapse after multidrug therapy for leprosy; a preliminary report in 22 cases in West. Nepal Lepr Rev, 1989; 60: 45-50.

14 Becx-Bleumink M. Relapse among leprosy patients treated with multidrug therapy. Experience in the leprosy control program of the All African leprosy and Rehabilitation Training Centre (ALERT) in Ethiopia: Practical difficulties with diagnosing relapses; operational procedure and criteria for diagnosing relapse. Int J Le pr, 1992; 60: 421-435.

15 Habtemariam H, Guebre-Xaber M. Lack of response to WHO/MDT: A case of report. Int J Le pr, 1993; 61: 632-633.

16 Abraham B, Cariappa A, Chacko CIG. Rifampicin in drug incorporated diet : effect of duration and temperature of storage. Relevance to drug susceptibility testing in mice inoculated with $M$. Leprae. Int $J$ Lepr, 1991; 59: 68-75.

17 World Health Organization. Laboratory techniques for leprosy 1987, Geneva. pp: 78-82.

18 Shetty VP, Vidyasagar PB, Antia NH. Study of evolution of nerve damage in leprosy. Part III-sciatic nerve lesions in mice inoculated with M. leprae with nerveconduction velocity correlates. Ind J Le pr, 1980; 52: 26-47. 